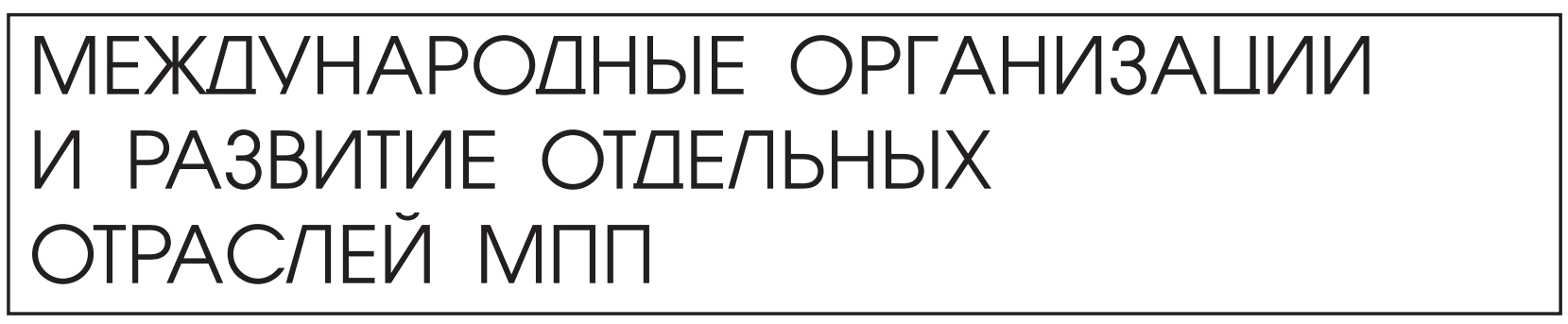

Шугуров М.В

\title{
ДЕЯТЕЛЬНОСТЬ ВОИС В СФЕРЕ МЕЖДУНАРОДНОЙ ПЕРЕДАЧИ ТЕХНОЛОГИЙ: НАПРАВЛЕНИЯ И ПРИОРИТЕТЫ
}

Аннотация. Предметом исследования является такое тематическое направление деятельности Всемирной организации интеллектуальной собственности как "патенты и передача технологий". Автор подробно останавливается на анализе прямой и подразумеваемой компетеничи организачии в данной сфере международного сотрудничества. Особое внимание уделяется специфике деятельности ВОИС в сфере патентной системы в ее национальном и международном измерении в аспекте ее воздействия на международныи трансфер технологий. Помимо этого автор анализирует проектную деятельность данной организачии в области патентов, воздействующей на передачу технологий в кроссграничном аспекте. Помимо этого детально исследована политика ВОИС в сфере промышленной собственности, предполагающая согласование интересов развитых и развивающихся государств применительно к охране промышленной собственности и защиты патентных прав, дуалистическим образом воздействующих на доступность технологий. В основу исследования положен системный метод, позволивший сформировать полные и исчерпывающие представления о многообразных направлениях деятельности организачии в тематической сфере "патенты и передача технологий". Также автор использует сравнительный метод, позволяющий понять особенности работы ВОИС в сфере содействия передаче технологий в целях развития в контексте сопоставления с деятельностью других международных организаций. Основными выводом проведенного исследования является обоснование связи между политикой ВОИС в сфере развития права промышленной собственности и патентной системы, с одной стороны, и позиционированием данной организации в качестве института развития, нацеленного на облегчение доступа к технологиям, - с другой. Особым вкладом автора в исследование темы стало проведение детального анализа практически всех направлений деятельности организации в сфере адаптации права ИС к новым условиям международного технологического обмена. Новизна исследования заключается в том, что автор обосновал вывод о новой парадигме, которой придерживается в своей работе данная организация, которая, движимая собственной Повесткой развития, нацелена в последнее время не просто на содействие в доступе развивающихся стран к технологиям, но на разворот международного технологического трансфера на содействие формированию в развивающихся государствах собственного национального технологического потеничиала.

Ключевые слова: Промышленная собственность, технологии, развиваюшиеся государства, технологический трансфер, формирование потенциала, зеленые техно- 
логии, патентная система, технологическая платформа, патетная информация, Соглашение ТРИПС.

Abstract: The subject of this research is such aspect of the work of the World Intellectual Property Organization (WIPO) as "patents and transfer of technologies". The author carefully examines the direct and implied competence of the organization in this area of international cooperation. A special attention is given to the specificity of the work of WIPO in the sphere of patent system in its national and international dimensions in the aspect of this influence upon the international transfer of technologies. The author also analyzes the projection work of this organization in the area of patents, which affects transfer of technologies in the transboundary aspect. The article also presents the detailed research of WIPO policy in the area of industrial property, which suggests agreement of interests of developed and developing countries with regards to protection of industrial property and patent right, dualistically impacting accessibility of technologies. The main conclusion consists in substantiation of connection between the WIPO policy in the area of development of law of industrial property and patent system on one hand, and positioning of this organization as a development institution aimed at easing access to technologies - on the other. The scientific novelty of this research lies in the fact that the author justified the thesis on the new paradigm that is used by this organization in their work, which being driven by its own development agenda, is lately aimed not only at assistance in access to technologies for developing nations, but at turning the international technological transfer towards assistance with formation of national technological potential in developing countries.

Keywords: TRIPS Agreement, patent information, technological platform, patent system, green technology, capacity building, technology transfer, technology, developing countries, industrial property.

условиях глобализации экономики наиболее важным ресурсом социально-экономического развития стали знания и технологии, передаваемые и распространяемые не только на национальном, но и международном уровне в коммерческой и некоммерческой формах. Международный технологический трансфер способен выполнять и еще одну функцию, а именно - содействовать преодолению сохраняющегося и постоянно модифицирующегося разрыва в уровне знаний и технологий между странами [1]. Успех в достижении данной цели зависит от модели международного технологического трансфера, имеющего, помимо всего прочего, и некоторые негативные последствия, например, сохранение технологической зависимости развивающихся стран от стран развитых. Поэтому особое значение проблеме передачи технологии придается на переговорах между данными группами государств, особенно, в контексте технического сотрудничества [2], либерализации торговли и охраны окружающей среды, а также, безусловно, воздействия прав интеллектуальной собственности (далее - ИС) на международный трансфер технологий.

В настоящее время международный трансфер технологий представляет собой институционализированную систему международных отношений экономического и внеэкономического характера, важнейшими акторами которых выступают некоторые международные организации, выполняющие определенные функции в поощрении международной передачи технологий в 
кроссграничном контексте. Первая заключается в стимулировании трансграничной передачи технологий через выработку механизмов для решения практических проблем, возникающих в частном и публичном секторе технологического обмена. Вторая заключается в том, что они являются своего рода форумами для переговорного процесса в отношении прав и обязанностей различных государств на международном уровне с целью сокращения имеющихся и возможных препятствий на пути международного трансфера технологий.

Среди крупнейших международных организаций, которые интегрированы в международную передачу знаний и технологий, следует упомянуть Всемирный банк и ЮНКТАД. Если говорить в целом, то различные международные организации либо включают в свою деятельность вопросы содействия передаче технологий через оказание технической поддержки, либо изначально специализируются в данной сфере, как, например, ЮНИДО.

К первого рода организациям относится ВТО. Так, в компетенцию Совета ТРИПС и Рабочей группы ВТО по торговле и трансферу технологий традиционно входит обсуждение проблем в данной сфере международного сотрудничества. Одновременно нельзя не упомянуть Всемирную организацию интеллектуальной собственности (далее - ВОИС), в рамках которой сразу три подразделения обсуждают проблемы трансфера технологий. Это - Рабочая группа по РСТ (Working Group on Patent Cooperation Treaty), Руководящий Комитет по патентному праву (Standing Committee on Law of Patents/SCP) (далее - ПКПП) [3] и Комитет по развитию и ИС (Committee on Development and the IP/ CDIP) (далее - КРИС) [4]. Как и в случае ВТО, дискуссии в рамках ВОИС не привели в настоящее время к выработке блока норм, предназначенных для продвижения вперед в существующих международных обязательствах по трансферу технологий. Тем не менее, значение деятельности ВОИС, как и BTO, в данном направлении международного сотрудничества состоит в постановке и выработке возможных решений в отношении такого коренного для международной передачи технологий вопроса, как воздействие прав ИС на эффективность соответствующей передачи и достижение ее целей, понимаемых в контексте Целей развития тысячелетия, сформулированных ООН.

В качестве методологической ремарки выдвинем тезис о том, что в силу междисплинарного характера международной передачи технологий международные организации, работающие в данной сфере, а ВОИС здесь не исключение, стремятся к совместному сотрудничеству и взаимодополнению, одинаковым образом сотрудничая с конкретными государствами и неправительственными организациями. Однако у каждой организации, в том числе ВОИС, имеется своя специфика деятельности. Она заключается главным образом в разработке такой тематической сферы международного сотрудничества, как ИС и международный трансфер технологий.

\section{1. Специфика деятельности ВоИС} в сфере патентов и международного трансфера технологий. Вполне очевидно, что права ИС, прежде всего патентные права, должны использоваться, применяться и защищаться так, чтобы технологии как глобальный ресурс развития содействовали бы всеобщему процветанию. Это требует корреляции глобальной политики защиты прав ИС, глобальной политики развития и глобальной политики технологического сотрудничества. Дело в том, что существующая модель международной системы защиты прав ИС способствует закреплению технологического разрыва, воспроизводимого соответствующей моделью технологического 
трансфера. Эта ситуация вызывает озабоченность не столько развитых государств, сколько международных организаций, работающих в сфере развития, в том числе ВОИС.

Как таковой тематический блок «ИС и передача технологий» проистекает из статьи 1 Соглашения между ООН и ВОИС 1974 года, которая предусматривает, что ООН признает ВОИС в качестве специализированного учреждения, ответственного, помимо всего прочего, за облегчение передачи технологии развивающимся странам, относящейся к промышленной собственности, в целях ускорения экономического, социального и культурного развития, с учетом компетенции других специализированных учреждений системы $\mathrm{OOH}$ [5]. Таким образом, компетенция ВОИС - это содействие тому, чтобы права ИС содействовали бы передаче технологий в целях развития. Отсюда следует, что содержательный формат работы организации заключается в сопряжении трансфера технологий и вопросов места ИС в современной экономике знаний.

ВОИС проявляет активную работу в данном направлении с тем, чтобы предложить возможные политические инициативы в сфеpe ИС, которые, действительно, содействовали бы справедливой передаче технологии, облегчению доступа к ней развивающихся и наименее развитых государств в целях развития.

В целом, надо сказать, проблематика соотношения патентов и передачи технологий с особой энергичностью обсуждается ВОИС в течении именно последнего десятилетия, особенно с 2005 года, в рамках разнообразных семинаров и конференций по различным вопросам права ИС, а также на уровне подразделений организации. ВОИС проводит по данной проблематике специальные мероприятия, например, в 2007 году был проведен коллоквиум «Патенты и передача технологий» (6 ноября 2007 года) [6]. Нельзя не упомянуть также и серию семинаров по экономике и интеллектуальной собственности, на которых поднимаются вопросы разработки соответствующей политики по вопросам передачи и диффузии технологий, ИС и инновационного развития экономики [7]. Цель семинаров - раскрытие всех деталей относительно влияния политики в области ИС на эффективность экономики, что логическим образом привлекло внимание участников к роли патентов в экономике интеллектуальной собственности и инноваций, так и к рынкам патентов и состоянию лицензирования в различных регионах. К наиболее заметному событию можно отнести проведение специального семинара по патентам и передаче технологий 5 декабря 2011 года накануне 17 сессии КРИС [8].

Сказанное означает, что ВОИС выступает в качестве специализированной организации, непосредственная компетенция которой в сфере развития и защиты прав ИС в силу их тесной связи с технологическими инновациями прямым образом приводит к развитию и проявлению ее подразумеваемой компетенции. К последней можно отнести крупномасштабную деятельность по аналитической работе в сфере тематического направления «ИС и инновации», в которую как раз и включено такое направление, как «ИС и передача технологии», интегрированное в наиболее общее направление «экономика ИС», которое нацелено на обеспечение лучшего понимания экономического воздействия ИС и роли политики в сфере ИС в рамках национальных экономических стратегий [9]. В качестве подтверждения сошлемся на доклад «Глобальный обзор ИС - изменяющееся лицо инноваций» (2011г.) [10].

В сущности, в данном докладе зафиксированы основные черты современного инновационного развития, в частности, его открытый и глобализирующийся характер, свойственный созданию и коммерциали- 
зации инноваций. Соответственно, дается объяснение предпосылкам растущей заинтересованности правами ИС и тем более ростом рынков технологий и прав на них. Несмотря на то, что данная публикация ВОИС в основном посвящена анализу инновационного процесса в условиях глобализации, определенное внимание в ней уделено международному лицензированию и механизмам совместной работы на основе ИС, включая государственно-частные партнерства. Организация принимала участие в составлении глобальных инновационных индексов 2012, 2013, 2014 и 2015 гг. [11], а также занимается подготовкой глобальных докладов по правам ИС. Так, подобный доклад за 2013 год был посвящен проблеме брендов, которые были в гл. 3 рассмотрены в контексте инноваций и конкуренции [12]. Необходимо добавить, что инициативы по преодолению барьеров на пути распространения технологий во всем мире основаны на серьезных исследованиях современной глобальной экономики знаний, которая характеризуется новыми конфигурациями потоков знаний и технологий и прав на них [13].

Напомним, что патенты и их воздействие на технологический трансфер стало одним из решающих вопросов международных дискуссий с самого начала данной повестки дня, в которые была интегрирована ВОИС. Так, в 1960-х гг. ООН предприняла изучение роли патентов в технологическом трансфере [14]. Начальной точкой была Резолюция ГА OOH 1713 (XXVI) «Роль патентов в трансфере технологий в слаборазвитые страны», предполагавшей проведение исследования воздействия патентов, в том числе зарубежных, на экономику развивающихся стран [15]. Вновь подтверждая, что доступ к запатентованным и незапатентованным технологиям, а также к управленческим технологиям является существенным для экономического и индустриального развития развивающихся стран, Ассамблея в своей Резолюции 2091 (ХХ) «Трансфер технологий в развивающиеся страны» [16] приветствовала международные инициативы по содействию передаче развивающимся странам соответствующих технологий. Далее данная работа была продолжена совместными усилиями ВОИС, ЮНКТАД и департамента экономики и социальных вопросов $\mathrm{OOH}$, которые увенчались в 1975 году крупномасштабным докладом [17].

Одним из судьбоносных моментов в деятельности ВОИС стало утверждение в 2007 году Повестки дня в области развития [18], которая призвана интегрировать соображения развития во все направления деятельности данной организации. Одновременно с этим Повестка продемонстрировала, что организация позиционирует в качестве важнейшего института международного развития наряду с Всемирным банком, ВТО и другими международными организациями. Для предмета нашего исследования наиболее интересны рекомендации, составляющие Повестку, выделенные в раздел С «Передача технологии, информационные и коммуникационные технологии и доступ к знаниям», а именно рекомендации $25,26,28$ - 31, которые содержат предложения, подчеркивающие ряд проблемных вопросов и ориентирующие на дальнейшие действия. Передача технологий также затрагивается в рекомендациях 22 и 23 раздела $\mathrm{B}$, посвященного нормоустанавливающей деятельности ВОИС.

Вместе с тем картина будет не полной, если не упомянуть одно важное обстоятельство, а именно то, что к тематике передачи технологий относятся и другие рекомендации, которые касаются таких вопросов, как установление справедливого баланса между ИС и интересами общества; учет специальных потребностей развивающихся государств, особенно наименее развитых; гибкие механизмы международных соглаше- 
ний в области ИС, которые обладают огромным потенциалом для достижения Целей развития, содержащихся в Декларации тысячелетия.

Столь масштабное включение вопросов, связанных с передачей технологий, в Повестку дня в области развития (и соответственно - распространение вопросов развития на передачу технологий), не является случайностью. Дело в том, что технологии, будучи ресурсом развития, раскрывают свой потенциал благодаря их использованию, что достигается путем их передачи. Поэтому передача технологий изначально включает аспект развития, который стал предметом системных исследований экспертов данной организации [19]. При этом обращает на себя то, что цель данного проекта - поиск путей сокращения разрыва в знаниях между развитыми и развивающимися государствами. По сути, ВОИС предстает как один из институтов развития, принявший на себя обязательство по оказанию развивающимся странам содействия в доступе к знаниям и технологиям.

Особая активность по обсуждению вопросов передачи технологий была развернута ПКПП начиная с января 2010 года. В качестве основы выступило предварительное исследование, которое было подготовлено Секретариатом [20]. Показательно, что данный документ подвергся пересмотру в связи с поступившими замечаниями и предложениями в рамках 16-ой [21] и 17-ой сессии [22]. Это говорит о неподдельной заинтересованности данной проблематикой. В результате реализации проектов и инициатив, направленных на исполнение рекомендаций Повестки дня, возникла потребность в системном осмыслении проделанной работы ВОИС в сфере передачи технологий. В этой связи на своей 17-ой сессии (5 - 10 декабря 2011 г.) ПКПП высказал заинтересованность в подготовке документа, в котором была бы отражена деятельность ВОИС в рассматриваемой сфере [23]. Данный документ был предложен Секретариатом на 18-ой сессии в 2012 году [24] и представляет собой системное изложение данного вопроса при опоре на анализ объемного эмпирического материала.

В свете сказанного следует внести некоторое уточнение. Дело в том, что международный трансфер технологий, как мы указали выше, это сложное институциональной образование. ВОИС как специализированная организация в сфере развития и охраны прав ИС не может заниматься всеми его аспектами. В ее компетенцию входит выявление и разрешение многочисленных проблем, связанных с воздействием патентов на международный трансфер технологий. Поскольку многообразные виды деятельности, осуществляемые ВОИС в сфере патентов прямо или косвенно сфокусированы на проблематике международной передачи технологий, то поэтому именно в данном ключе был составлен упомянутый выше документ о деятельности ВОИС в области передачи технологий 2012 года. В нем исследуется весь массив деятельности организации в области патентов, которая различным образом связана с передачей технологий. Надо учитывать, что ВОИС не является научно-технологической организацией, которая генерирует технологии и далее их передает. Но она воздействует на международный трансфер технологии в процессе своей многообразной деятельности в сфере развития патентного права и патентной системы, которая призвана создавать надлежащие условия для осуществления международной передачи технологий.

В этой связи хотелось бы процитировать п. 6, по сути, исторического документа 2012 года о деятельности ВОИС в сфере передачи технологий. Здесь сказано о том, что осуществляемые данной организаций мно- 
гообразные виды деятельности в области патентов не относятся напрямую к передаче технологий. Однако они интегрированы в данную проблематику, ибо «поощрение технологических инноваций и распространение и передача технологий достаточно широко признаются общими задачами патентной системы. В какой-то мере все усилия по совершенствованию патентной системы, прямо или косвенно, положительно сказываются на передаче технологий, либо путем развития правовых и институциональных основ, технической инфраструктуры, вспомогательных инструментов, усиления потенциала, либо путем повышения знаний в данной области».

Таким образом, организация исходит из того, что такие элементы патентной системы как высокая предсказуемость в отношении того, что касается сроков действия выданных патентов, достаточное раскрытие изобретений в заявках на патенты или адекватный объем охраны патентных прав с учетом их сбалансированности с исключениями и ограничениями, являются не только показателями высокого уровня развития патентной системы, но и прямым образом воздействуют на развитие инноваций и передачу технологий.

Из сказанного ясно, что ВОИС оказывает воздействие на международную передачу технологий не только путем совершенствования патентного права на международном и национальном уровне, но и совершенствования патентной системы в целом, включая международное сотрудничество в данной сфере. В этой связи хотелось бы указать на Доклад о международной патентной системе 2008 года [25]. Одновременно заметим, что многообразная деятельность организации в сфере патентного права и международной патентной системы дословно обозначается как деятельность в сфере патентов, многие направления которой, действительно, связаны с передачей технологий, как на национальном, так и международном уровне.

К направлениям данной деятельности относится - оказание технической помощи и укрепление потенциала в патентных областях, в том числе юридическое консультирование, а также подготовка государственных служащих и других заинтересованных лиц, осуществление образовательных программ, направленных на повышение уровня понимания вопросов ИС. Последнее направление особенно важно, так как распространение технологических знаний требует одновременного распространения правовых знаний, например, о том, кто является владельцем данной технологии, под юрисдикцией какого государств он находится, а также каков срок действия его прав. Если говорить в обобщенной форме, то ВОИС уделяет повышенное внимание также совершенствованию как правовой, так и общей подготовки работников патентных ведомств, патентных поверенных, экспертов, судей.

Нельзя не указать на то, что к передаче технологий самое непосредственное отношение имеет, например, деятельность Центра по арбитражу и посредничеству ВОИС. Центр предлагает альтернативные способы урегулирования споров в области международной торговли между частными сторонами. Данные способы нацелены на урегулирование споров главным образом в сере лицензионных патентных соглашений, соглашений по НИОКР, соглашений о создании совместных предприятий и передачи технологий. Последнее особо обращает на себя внимание, ибо в этом случае ВОИС не косвенно, а прямым образом входит в «материю» трансфера технологий.

В процессе анализа воздействия ВОИС на повышение эффективности международного технологического трансфера не следует думать, что она ограничивается лишь организационными мерами. Так, организация на 
сегодняшний день администрирует двадцать шесть международных соглашений в сфере прав ИС [26], что побуждает обратиться к высказыванию о том, что новый этап в развитии системы международного трансфера технологий связан с вступлением в силу Соглашения ТРИПС 1 января 1995 года, содержащего, как известно, гармонизированные минимальные стандарты защиты прав ИС, включая права промышленной собственности. Имплементация положений ТРИПС привела, с одной стороны, к глобализации прав ИС, а с другой - к преобладанию торгового, т.е. экономического подхода к передаче технологий на международном уровне. В целом соглашаясь с данным подходом, необходимо отметить, что для обеспечения международного трансфера технологий во всем мире не перестают оставаться актуальными международно-правовые соглашения, которые администрируются ВОИС. В данном контексте не следует также думать, что главной международной организаций в тематическом направлении «ИС и передача технологий» стала ВТО, а главным международным инструментом Соглашение ТРИПС.

В свете сказанного должен быть упомянут Договор ВОИС о патентом праве (PLT) 2000 года [27], содержащий правила в отношении процедурных требований в отношении ходатайств о внесении записи об изменении имени и адресат заявителя, внесении записи об изменении заявителя или владельца и, наконец, о внесении записи о лицензии и залоге, а также об исправлении ошибки. (Article 14.1(b)). Данные правила нацелены на преодоление необоснованной сложности национальных патентных процедур и предполагают обеспечение своевременной записи информации, относящейся к собственникам патентов и соответствующих лицензиях, и стремятся к своевременной и рациональной записи информации относительно право- обладателей и статуса лицензий. Конечно, положения Договора не имеют прямой связи с поощрением передачи технологий. Однако, данный Договор создает условия для защиты на международном уровне объектов промышленной собственности, генерируемых в развивающихся странах. PLT допускает, что патентные заявки регистрируются в рамках различных юрисдикций, и дает возможность ТНК регистрировать патентные заявки в большинстве развивающихся государств. Это гарантирует интенсификацию трансфера технологий в развивающиеся государств и поэтому содействует наращиванию международного трансфера технологий.

Особенность другого договора - Договора о патентной кооперации 1970 г. (РСТ) [28] заключается в том, что Договаривающиеся государства не только заявили в преамбуле Договора о стремлении внести вклад в прогресс науки и техники, а также в совершенствование правовой охраны изобретений, но и в стремлении стимулировать и ускорить экономический прогресс развивающихся стран. Договор предполагает конкретизацию общей установки на ускорение доступа публики к технической информации. содержащейся в документах, описывающих изобретения, применительно к потребностям развивающихся стран. Как результат, преамбула заявляет о необходимости принятия мер, которые предназначены повысить эффективность региональных и национальных правовых систем охраны изобретений, в том числе посредством обеспечения более быстрого доступа к информации об имеющихся технических решениях, отвечающих специфическим потребностям развивающихся стран. Во исполнение этих намерений ст. 50.3 закрепляет, что информационные услуги осуществляются в направлении особого содействия Договаривающимся государствам, которые являются развивающимися, в приобретении технических 
знаний и технологий, включая имеющиеся опубликованные ноу-хау.

Участие большинства развивающихся стран в PLT, PCT и других сходных соглашениях, а также укрепление их патентных систем приводит к увеличению потоков зарубежных патентных заявок в развивающиеся государства. Все это укрепляет технологический потенциал первых, но не автоматически, предполагая сохранение целого ряда проблем. Поэтому для ВОИС, помимо вопроса о воздействии патентов на международный трансфер технологий в целом, не перестает оставаться актуальным вопрос о воздействии положений администрируемых договоров на положение дел в международном трансфере технологий.

Иллюстрацией высказанного тезиса является содержание п. 8 документа 2012 года о деятельности ВОИС в сфере передачи технологии. Здесь прямо говорится о том, что нормальное функционирование РСТ в качестве международной системы подачи патентных заявок весьма существенно для международной патентной системьв во всех областях техники (Кстати говоря, за последние десять лет количество заявок, поданных по процедуре РСТ, удвоилось). Далее здесь отмечается, что «учитывая ее глобальный масштаб, качество и своевременное предоставление продуктов, таких как публикации заявок РСТ и отчетов о международном поиске, заключений о поиске и предварительной международной экспертизе, эта система оказывает влияние на качество национальных и региональных патентных систем». Таким образом, в очередной раз демонстрируется, что сфера ответственности организации - международная патентная система. Одновременно можно заключить, что именно от ее нормального функционального зависит не только технологическое развитие, но и эффективность международного трансфера технологий.
Для справедливости надо заметить, что ВОИС как организация-партнер ВТО, уделяя внимание воздействию положений ТРИПС и особенно ст. 7 на процессы патентования и, соответственно, на состояние МТТ, вносит свой вклад в широко развернувшуюся дискуссию о последствиях имплементации положении ТРИПС на международный трансфер технологий. Анализ данного воздействия осуществляется в рамках семинаров, проводимых организацией [29; 30], а также на уровне проводимых аналитических исследований [31]. В фокусе внимания экспертов организации находится также имплементация ст. 66.2 Соглашения ТРИПС, которая, как известно, закрепляет обязательства развитых стран стимулировать частный сектор, находящийся под их юрисдикцией, предпринимать усилия по передаче технологий в наименее развитые страны в целях создания жизнеспособной технологической базы [32].

К задачам ВОИС в сфере международной передачи технологий в условиях глобальной экономики знаний относится оказании содействия развивающимся государствам в их интеграции в глобальные цепочки добавленной стоимости. Для этого организация работает над задачей облегчения передачи технологий в данные страны посредством повышения уровня доступности технологий в форме осуществления многообразных направлений деятельности в сфере патентов - повышении осведомленности развивающихся стран относительно природы и значения процессов передачи технологий для их экономического развития, а также разработки способов не только приобретения, но и создания собственных результатов интеллектуальной деятельности применительно к национальным условиям. Последнее означает, что развивающиеся страны рассматриваются не просто как получатели технологий, но и как равноправные 
участники глобального научно-технологического прогресса в рамках экономики знаний. Поэтому ВОИС решает двуединую задачу укрепления их потенциала не только в сфере получения технологий, их последующей диффузии и использования, но и укрепления, а где это необходимо, создания потенциала для развития интеллектуальной деятельности и обеспечения инновационного процесса через коммерциализацию ее результатов. Это задает осуществление многообразной деятельности организации по разным направлениям.

\section{2. Проектная основа деятельности} ВОИС в области патентов, воздействующая на международный трансфер технологий. Организацией непосредственной работы по исполнению рекомендаций Повестки в 2007 году в соответствии с решением Генеральной Ассамблеи ВОИС занимается КРИС. К предмету его компетенции относится: разработка программы работы по выполнению рекомендаций Повестки дня; проведение мониторинга, оценки и обсуждения выполнения данных рекомендаций; составление отчета о проделанной работе в сотрудничестве с другими подразделениями ВОИС; обсуждение вопросов ИС и развития в соответствии с решениями Комитета и Генеральной Ассамблеи организации. В качестве способа выполнения рекомендаций Повестки дня в аспекте повышения международной передачи технологий выступают многообразные проекты [33], реализацию которых курирует КРИС.

Так, к проектам, которые направлены на создание и совершенствование в развивающихся странах необходимой инфраструктуры и профессиональных навыков для эффективного использования системы ИС в области инновационной деятельности и передачи технологий относится проект DA_10_03, который реализуется в соответствии с рекомендацией 10 Повестки дня с
2010 года [34]. Проект интересен тем, что предусматривает шаги, направленные на управление правами ИС в академических и научно-исследовательских организациях, включая создание отделов трансфера технологий, развитие навыков точного описания изобретений. Разумеется, данный проект адресован, прежде всего, развивающимся государствам.

В качестве другого, сходного по своей тематике проекта можно указать на проект DA_19_30_31_02, реализуемый в связи с рекомендациями 19, 30 и 31 с 2010 года. Цель проекта - содействовать формированию и развитию потенциала на национальном уровне для использования необходимой научно-технической информации как соответствующей технологии, выступающей ресурсом для решения проблем развития, которые характерны для наименее развитых стран. Проект должен определять возможности предоставления людям, сообществам и организациям в данных государствах необходимых технологий, которые необходимы для эффективного и практического применения с помощью соответствующих навыков. Иными словами, мерами по повышению потенциала развивающихся стран в сфере ИС и патентов являются проекты и программы ВОИС по созданию и укреплению национальных кадров в сфере использования прав ИС как инструмента создания инноваций в рамка НИОКР с их последующей коммерциализацией.

Не менее важными для общего состояния международного трансфера технологий оказываются направления деятельности ВОИС в сфере патентной информации и совершенствовании ее инфраструктуры. Они представляют собой постоянный пересмотр и обновление Международной патентной классификации (МПК) и стандартов ВОИС в целях облегчения поиска, получения, использования и распространения патентной 
информации. Дело в том, что опубликованные патенты и патентные заявки, а также связанные с ними материалы представляют собой совокупность очень ценных источников информации, устанавливающих связь между возможными поставщиками и возможными получателями технологий. Вполне понятно, что в век ИКТ возникают новые условия для более эффективного функционирования системы патентной информации, в частности, возможностей доступа к последней. Поэтому ВОИС стремится создавать глобальные базы данных и обеспечивает доступ к ним.

В качестве одной из глобальной базы данных ВОИС выступает PATENTSCOPE. Организация предоставляет свои услуги в области патентной информации, опираясь на эту базу, что также можно рассматривать как содействие в передаче технологии. Обратим внимание на то, что с 2012 года данная система обеспечивает бесплатный поиск по более чем 10 млн. патентных документов, включая более чем 2 млн опубликованных заявок РCТ, таким образом облегчая и ускоряя доступ к технической информации и новым изобретениям. Стоит также сказать о том, что база PATENTSCOPE взаимодействует с национальными патентными фондами, которые входят в последнюю. В результате выстраивается своего рода сеть, ориентация в рамках которой возможна благодаря системе лингвистических средств, позволяющих проводить многоязыковой поиск и осуществлять перевод названий изобретений и их рефератов. В результате данная база позволяет осуществлять полнотекстовый поиск по опубликованным международным заявкам РСТ, начиная с 1978 года, и более того - по 25 национальным и региональным фондам. Также она обеспечивает поиск по документам на национальной фазе заявочной процедуры из более чем 40 стран, а также позволяет осуществлять загрузку еженедельных сборников опубликованных заявок по подписке.

Несмотря на то, что техническая сторона ИС, представляющая собой технологическую инфраструктуру распространения патентной информации о заявках и зарегистрированных патентах, не является сама по себе элементом передачи технологий, ее модернизация, в конечном счете, создает необходимые условия для передачи технологий. Поэтому столь значимый акцент ставится на развитии систем, позволяющих национальным патентным ведомствам эффективно, а также своевременно распространять и получать патентную информацию в цифровой форме. Поэтому ВОИС оказывает развивающимся странам содействие в отработке систем (технологической инфраструктуры) для оцифровки патентной информации и ее распространения через Интернет.

Одновременно с этим организация задействует ресурсы своей базы PATENTSCOPE с целью оказания поддержки лицензированию в соответствии с рекомендацией Рабочей группы по РСТ. Речь идет о запуске новой функции данной базы патентной информации. Так, с помощью этой функции те заявители, которые заинтересованы в лицензировании своих изобретений на уровне международных заявок, обрели возможность разместить эту информацию на веб-сайте PATENTSCOPE. Они имеют возможность заполнить новый формуляр «Запрос на указание о возможности лицензирования» или направить письмо с указанием изобретения (или изобретателей), которые доступны для лицензирования. К тому же, они могут включить в формуляр или письмо дополнительные условия для получения лицензии. Указание на возможность лицензирования может быть сделано на любом этапе с подачи международной заявки и вплоть до окончания 30 месячного срока. Данное указание отражается в библиографических данных 
заявок на вкладке «Библиографические данные» до окончания 30 месячного срока на странице PATENTSCOPE.

На уровне технической помощи отдельным государства организация оказывает поддержка в модернизации инфраструктуры ИКТ в патентных ведомствах, а также в оцифровке патентных фондов, поддержке наращивания потенциала в целях использования тех или иных инструментов получения патентной информации. В результате содействие совершенствованию инфраструктуры доступа к патентной информации, а также модернизация работы патентных ведомств является условием эффективного распространения знаний и технологий.

В качестве тематического проекта в данном направлении необходимо указать на Проект DA_08_01, реализуемый в соответствии с рекомендацией 8 с 2009 года [35]. В качестве цели проекта выступает облегчение доступа к техническим знаниям пользователям из развивающихся и наименее развитых стран, в том числе региональным и субрегиональным организациям, работающим в сфере ИС. Обеспечение доступа позволит использовать знания и через них стимулировать экономический рост на инновационной основе. Для реализации данного проекта в 2010 году был подготовлен сопроводительный документ, в котором был осуществлен обзор как патентных, так и непатентных баз данных с одновременным выдвижением предложений по критериям для выбора баз данных в соответствии с анализом потребностей патентных ведомств и местных клиентов. Далее был подготовлен Справочник по базам данных, в котором был указан их объем и функциональные возможности.

В рамках анализируемого проекта с июля 2009 года стала реализовываться программа «Доступ к результатам научных исследований для развития и инноваций (ARDI)». Цель программы - усилить спо- собность развивающихся государств участвовать в глобальной экономике знаний, поддерживать усилия исследователей из развивающихся государств в создании и развитии новых решений в отношении технологических вызовов, стоящих на локальном и глобальном уровне [36]. Программа предполагает доступ к 20000 книг, журналов и реферативных работ для 117 государств и отдельных регионов, а также широкий доступ к патентной информации из различных отраслей науки и техники, не говоря уже о доступе к инструментам международного патентного права. Обращает на себя внимание то, что доступ для наименее развитых стран является бесплатным, а для развивающимся - по минимальной доступной цене с согласия издателей.

Нельзя не отметить и запуск с 2010 года аналогичной программы «Доступ к специализированной патентной информации (ASPI)» [37], нацеленной на то, чтобы обеспечить для наименее развитых стран бесплатный доступ к патентным базам данных, а для некоторых развивающихся государств - доступ по сниженным ставкам. На сегодняшний день шесть ведущих провайдеров патентных баз данных (LexisNexis, Minesoft, Proquest, Thomson Reuters, Questel, WIPS) предоставили такой доступ. В результате запущенного проекта, в рамках которого ВОИС сотрудничает с указанными провайдерами коммерческих патентных баз данных, увеличились возможности доступа к патентной информации для развивающихся государств.

Стоит обратить внимание на то, что, если проект DA_10_03 предусматривает содействие созданию отделов по передаче технологий в научно-исследовательских учреждениях, то данный проект - создание сети центров поддержки технологий и инноваций (TISC) [38], которые будут оказывать помощь в области патентной и непатентной 
информации, информации относительно ИС и инноваций местным пользователям в развивающихся странах, а также оказание содействия в ознакомлении и обмена передовым опытом в этой области.

В тесной связи с рассмотренным проектом выступает проект DA_19_30_31_01, реализуемый в соответствии с рекомендациями 19, 30 и 31 с 2010 года [39]. В рамках проекта предусматривается предоставление развивающимся странам услуг, которые облегчили бы использование патентной информации именно о конкретной технологии с тем, чтобы способствовать, в сотрудничестве с другими межправительственными организациями развитию местной инновационной и научно-исследовательской деятельности. Обращает на себя внимание включение в данный проект отчетов о nатентных ландшафтах (здравоохранение, сельское хозяйство, экология и т.д.) и существующих правах ИС по отдельным технологическим областям.

Данное направление далеко не случайно, ибо предназначение технологий - не только быть фактором экономического прогресса, но и фактором развития человека и общества. Отсюда внимание организации ко всем технологиям, которые релевантны развитию. Это нашло свое отражение в тематике работы конференции по вопросам ИС и государственной политики, которая состоялась 13 - 14 июля 2009 года в Женеве [40]. В предметное поле обсуждения вошли вопросы взаимосвязи ИС с различными сферами государственной политики, включая проблемы доступа и передачи технологий в области изменения климата, здравоохранения и продовольственной безопасности.

В связи с тем, что вопросы доступа и передачи технологии интересуют также и другие международные организации, то отсюда вполне объяснимо сотрудничество ВОИС, например, с ВОЗ и ВТО по вопросам доступа к запатентованными и незапатентованным лекарственным средствам, что выступает элементом права человека на здоровье и, соответственно, соотносится с деятельностью по содействию развитию. В качестве одного из примеров совместной работы можно привести совместный симпозиум по вопросам доступа к лекарственным средствам, патентной информации, свободе действий, передаче технологий и определении приоритетов научных исследований в области здравоохранения. В центре внимания участников оказались вопросы статуса патентов на лекарства, которые были включены в типовой перечень жизненно важных лекарственных средств ВОЗ. Параллельно с этим, был проведен обзор двух патентных ландшафтов по антиретровирусным препаратам и вакцинам, а также баз данных по патентам на некоторые лекарства от ВИЧ инфекции, которая была создана Патентным пулом лекарственных средств совместно с ВОИС.

Анализируя работу организации, надо также указать на еще один важный инфраструктурный проект. Мы имеем в виду разработку технологических платформ как новой формы технологического развития, успешно апробированного в ЕС. Технологические платформы представляют собой форму партнерства между поставщиками и получателями технологий. В настоящее время в рамках ВОИС созданы две платформы - WIPO Re:Search [41] - «Обмен инновациями в борьбе с игнорируемыми тропическими заболеваниям» и WIPO Green в области экологических технологий.

Задачей первой платформы является налаживание партнерства с фармацевтическими компаниями, научно-исследовательскими учреждениями и НПО BIO Ventures for Global Health. Данная платформа предоставляет доступ к ИС по фармацевтическим соединениям, технологиям, ноу-хау и 
другим данным для исследований в области игнорируемых тропических заболеваний. Платформа представляет собой общедоступную базу данных с возможностью поиска, специализирующегося в области права ИС и ресурсов для формирования новых партнерств и поддержки организаций, проводящих исследования в области лечения игнорируемых тропических заболеваний. В дополнении к сказанному отметим, что ВОИС активно изучает возможность создания интернет-ресурса для поиска патентной информации в области жизненно важных медицинских технологий в разных юрисдикциях с рабочим названием «WIPO essential».

C нашей точки зрения одной из наиболее масштабных инициатив не только в рамках деятельности ВОИС, но и глобальной политики в сфере ИС и международного трансфера технологий в целом, является Проект DA_19_25_26_28_01《Интеллектуальная собственность передача технологий: общие проблемы - нахождение решений», реализуемый под эгидой КРИС и направленный на выполнение рекомендаций Повестки дня, прямо или косвенно затрагивающих проблемы повышения эффективности международного трансфера технологий. Первоначальный вариант Проекта был предложен вниманию на третьей сессии Комитета (27 апреля - 1 мая 2009 года), но из-за того, что его рассмотрение не состоялось, был вынесен на обсуждение в рамках четвертой сессии [42]. Проект, базирующийся на Рекомендациях 19, 25, 26 и 28 ПДР, был принят в виде проектного предложения на 6-й сессии КРИС (Женева, 22 - 26 ноября 2010 года) [43], а далее в 2011 году - в виде проектного задания [44] и был рассчитан на 2011 - 2013 гг. Окончательный пересмотр данного проекта был осуществлен в рамках девятой сессии КРИС [45]. В ходе реализации проекта сроки были продлены, а некоторые мероприятия осуществляют и после формального завершения проекта. Впереди - внедрение результатов проекта в проекты ВОИС.

В Проекте не только предусмотрены конкретные действия (проведение исследований, совещаний и форумов на региональном и международном уровне в сфере ИС и передачи технологий) по достижению его целей, но и поэтапный план их выполнения. Особый акцент поставлен на выработку предложений по совершенствованию передачи технологий в развивающиеся и наименее развитые страны, в том числе посредством поиска более эффективных механизмов сотрудничества в сфере ИС и трансфера технологий. Иными словами, основной смысл проекта - выработка предложений по выработке согласованной политики в области ИС и ее совершенствованию с целью поощрения передачи технологии. Обращает на себя внимание то, что содержание проекта далеко выходит за рамки сугубо патентной проблематики и затрагивает экономические вопросы, поддержку инноваций вне рамок существующей патентной системы, политические инициативы в отношении установления партнерских отношений в бизнес-среде и т.д.).

Как отмечается в одном из рабочих документов КРИС, основная задача проекта заключатся в содействии изучению, более широкому пониманию, а также достижению консенсуса в отношении возможных инициатив и политики, связанных с ИС для активизации процесса передачи технологии, особенно на благо развивающихся стран, а также в разработке Новой платформы для международного сотрудничества в области ИС и передачи технологии, которая будет основываться на реалистичных, не противоречивых и взаимоприемлемых элементах, являющихся отправной точкой для нахождения совместных решений [46]. Проект предусматривает применение поэтапного 
подхода, предполагающего участие аккредитованных организаций и новых партнеров во всех аспектах деятельности по передаче технологий. В его рамках предусматривается исследование политики в отношении ИС и новые инициативы, необходимые для активизации процесса передачи и распространения технологии, в особенности в интересах развивающихся стран. Параллельно с этим предполагается налаживание международного сотрудничества в области ИС.

В целом проект оценивается в качестве надежной отправной точки для ряда действий, направленных на определение соответствующей политики и практики в сфере ИС, которые должны использоваться для продвижения трансфера и распространения технологий в развивающиеся и наименее развитые страны.

Стоит обратить внимание на то, что КРИС получил целый ряд комментариев к данному проекту от развитых и развивающихся стран. В своих комментариях государства предлагали подвергнуть Проект модификации с точки зрения повышения его эффективности. В процессе обсуждения было предложено трансформировать его в проект «Доступ к знаниям и технологиям», который должен фокусироваться на потребностях развивающихся и наименее развитых государств для формирования эффективной модели трансфера технологий.

Если говорить о результатах реализации проекта, то они подверглись системной оценке [47]. В специальном концептуальном документе были сделаны обобщения относительно коренных причин проблем, которые осложняют международную передачу технологий [48]. Эксперты ВОИС пришли к выводу о том, что не все запланированные мероприятия удалось выполнить. В этой связи был предложен целый ряд рекомендаций, среди которых, например, - совершенствование веб-сайта, посвященного передаче технологии (От себя заметим, что в рамках Всемирного банка, например, аналогичный сайт показал хорошие результаты работы). Одновременно это говорит о том, что ВОИС движется к выделению проблематики передачи технологии в качестве самостоятельного направления своей деятельности. Данный вывод подтверждают результаты одной из самых последних инициатив в рамках Проекта - проведение Форума экспертов высокого уровня по вопросам международной передачи технологий (Женева, 16 - 18 февраля 2015 года) [49], решение о проведении которого было принято на 14-ой сессии КРИС [50]. На Форуме были выработаны рекомендации относительно усиления роли ВОИС в расширении масштабов передачи технологий в рамках повестки дня в области развития на основании создания технологических платформ [51]. Одновременно с этим были высказаны рекомендации о необходимости более интенсивной работы с негосударственными акторами передачи технологий, например, с частным сектором. Данная работа уже проводится организацией [52], хотя и требует своего развития.

\section{3. Проблема гибкой системы права} ИС в контексте проблемы согласования интересов развитых и развивающихся гоcyдapcmв. К одной из значимых инициатив ВОИС в области патентов, воздействующей на состояние дел в международном технологическом трансфере, является движение в направлении к созданию механизма мониторинга практики соглашений по передаче технологий, а именно лицензионных соглашений. В 2012 году секретариат ВОИС направил вопросник государствам-членам с целью получения существенной информации об опыте, приобретенном на национальном уровне по взаимодействию между соглашениями по передаче технологий и антимонопольным законодательством. Подобная инициатива была предпринята в 
рамках Рекомендации 23 Повестки ВОИС в области развития. ВОИС разъясняет, что антимонопольный аспект передачи технологий принимался во внимание многосторонней повестки, начиная с 1960 годов в рамках исследования роли патентов в передаче технологий в развивающиеся страны.

Известно, что Генеральная Ассамблея ООН резолюцией 35/63 от 5 декабря 1980 года приняла «Комплекс многосторонне согласованных принципов и правил по контролю за ограничительной деловой практикой» [53]. Однако она далее не смогла стать основой для связывающего международного документа, в котором были заинтересованы развивающиеся страны. Несмотря на неудачу принятия Международного кодекса поведения в сфере передачи технологий, тем не менее, Проект Кодекса ЮНКТАД 1985 года о поведении в сфере передачи технологий продолжает оставаться источником стандартов наилучшей практики в сфере международной передачи технологий. Отметим, что ВОИС дополняет деятельность, которую начала ЮНКТАД, в течение ряда лет инициировавшая дискуссию о гармонизированных критериях с тем, чтобы включить, в конечном счете, антиконкурентную клаузу в лицензионные соглашения по передаче технологий.

Антимонопольное законодательство является действенным средством для борьбы с ограничительной деловой практикой в сфере передачи технологий, так как сокращает число случаев злоупотребления правами ИС. Развивающиеся страны поняли это и взяли под контроль ограничительную практику, используя возможности антимонопольного законодательства еще в 1980-1990х гг. Значение антимонопольного законодательства заключается в поддержании баланса системы права ИС, что позволяет разрешить противоречия между правами ИС и правом на доступ к технологиям, как, впрочем, и другими результатами интеллектуальной деятельности. Для успешного процесса международной передачи технологий важное значение имеют не только гибкие возможности, но и антимонопольные механизмы, которые связаны между собой. Роль антимонопольных механизмов склонны обсуждать как развитые, так и развивающиеся государства.

Как показывает ВОИС в рамках первого обзора поступивших ответов государств в отношении регистрации лицензионных соглашений в сфере передачи технологии и включении в них антиконкурентной клаузу, основой для дискуссий и принятия конкретных мер выступают положения ст. 40 ТРИПС [54]. Так, ст. 40.1 гласит о том, что некоторые виды лицензионной практики или условий, относящихся к правам ИС, которые ограничивают конкуренцию, могут иметь неблагоприятное воздействие на торговлю и препятствовать передаче и распространению технологий. Статья 40.2 предусматривает право государств - участников устанавливать в своем законодательстве виды лицензионной практики или условия, которые в некоторых случаях могут выступать в качестве злоупотреблений правами ИС, что оказывает негативное воздействие на конкуренцию на соответствующем рынке. Исходя из этого, государство - участник вправе принять надлежащие меры по предотвращению данной практики (например, исключительные условия по обратной передаче покупателем лицензии технической информации продавцу лицензии; условия, предотвращающие оспаривание юридической силы; принудительный пакет лицензионных условий) или контролю над ней в свете соответствующих законов и правил этого государства - участника.

Из этого можно сделать вывод о том, что Соглашение ТРИПС примечательно не только перечнем гибких механизмов в сфере прав ИС, но и допущением возможности ис- 
пользования на национальном уровне антимонопольных механизмов. В результате, как показывает T. Nguyãĕn, фокусирующийся на гибких механизмах ТРИПС применительно к контролю за антиконкурентной практикой в лицензионных соглашениях, развивающиеся страны обладают правом использовать национальное конкурентное право для того, чтобы содействовать доступу к технологиям в целях защиты национальных интересов и благополучия потребителей [55, pp. 7 -8]. Во втором обзоре 2015 года ответов государств ВОИС еще более подробно обращается не только к положениям ТРИПС, но и к практике ЕС в сфере лицензирования передачи технологий [56].

Следует напомнить, что эффективный технологический трансфер возможен только в условиях гибкой патентной системы, в которой прежде всего заинтересованы реципиенты технологий - развивающиеся государства. Достаточно интересно отметить, что данные страны считают, что технологический трансфер не предназначен к тому, чтобы представлять собой преимущественное пространство действия патентных прав. Об этом они прямо высказываются в ходе заседаний соответствующих подразделений ВОИС. Так, в соответствии с комментарием Колумбии к проекту ВОИС «Интеллектуальная собственность и передача технологий», технологический трансфер не может поддерживаться как условие для осуществления прав ИС или обоснованности регистрации. Далее здесь было указано на то, что баланс между правами ИС и публичными интересами в целом находится в рамках механизмов, которые предоставляет система прав ИС, включая гибкие механизмы в международных соглашениях [57, С. 1]. Вместе с тем развивающиеся страны осознали роль защиты патентных прав в качестве стимула для технологических инноваций. Об этом говорит осуществленная ими модернизация национальных патентных систем.

Для развивающихся стран вполне обоснованно добиваться от развитых стран дальнейших, даже еще больших обязательств и имплементации уже имеющихся обязательств в отношении содействия трансферу технологий без ущерба для достигнутого уровня защиты прав ИС. Поэтому видение прав ИС как однозначного препятствия на пути трансфера технологий постепенно исчезает. Так, в упомянутом комментарии Колумбии выражено несогласие с подходом, согласно которому ИС блокирует технологический трансфер. Представители Колумбии подчеркнули, что уместно определить, что ИС обеспечивает систему стимулов, которые содействуют творчеству и генерированию инноваций и что без ИС не существует стимула для технологического прогресса, а, значит, и для передачи технологий. Колумбийская делегация сослалась на документ национального экономического и социального Совета Колумбии (CONPES) «Основания плана действий для поддержки системой интеллектуальной собственности национальной конкурентоспособности и производительности 2008 - 2010 гг.», в котором содержится пункт, посвященный стратегии в сфере эффективного применения прав ИС [58, Р. 2]. Стратегия заявляет достижение соответствующего осуществления правил в сфере ИС, которые представляются существенными для национальных и иностранных инвестиций и технологического трансфера ИС, а также предусматривает гарантии уважения экономических прав креаторов посредством стимулирования креативности.

Однако такой подход характерен не для всех развивающихся стран. В качестве примера можно привести позицию группы стран со сходными интересами (like-minded group), представленной Египтом, Индией, ЮАР и 
др., которые требовали в ПКПП продолжения исследования, которое фокусировалось бы на негативных аспектах воздействия патентов на трансфер технологий.

Думается, что такие требования имеют под собой объективные основания, заключающиеся в воздействии на эволюцию международных стандартов в сфере охраны патентных прав представлений развивающихся стран о значении патентной охраны результатов интеллектуальной деятельности. Общая позиция развитых стран заключается в том, что хорошо смоделированная система прав ИС является существенным инструментом для экономического развития и трансфера технологий. Однако развитые страны, обладающие наибольшей ответственностью за глобальное технологическое развитие и использование технологий в целях развития, также начинают осознавать негативный эффект от несбалансированного усиления защиты прав ИС в отношении развития технологического обмена. Так, Великобритания в одном из своих комментариев в рамках работы КРИС высказала мнение о том, что любое изучение вопроса о влиянии ИС на трансфер технологий должно быть сбалансированным и учитывать, как позитивные, так и негативные аспекты подобного воздействия. Таким образом, проведенные дебаты в рамках КРИС демонстрируют не только различия подходов развитых и развивающихся стран к перспективам дальнейшей эволюции права ИС и его воздействия на МТТ, но и точки совпадения, что может в дальнейшем положительным образом сказаться на повышении результативности передачи технологий в развивающиеся страны.

Кстати говоря, ВОИС анализирует уже имеющиеся и возможные инициативы развитых государств по формированию действенной политики содействия передаче технологий в развивающиеся страны (раскрытие информации об изобретениях, повышение доступности патентных данных для развивающихся государств, принудительное лицензирование для целей экспорта важнейших технологий в развивающиеся страны и т.д.)[59], которые должны сочетаться с инициативами стран развивающихся (инвестиции в развитие инфраструктуры, повышение уровня охраны ПИС, реформирование патентного законодательства и т.д.) [60]. Точкой совпадения должно стать общее видение необходимости гибкой системы прав ИС, стандарты которой заложены в так называемых гибких механизмах ТРИПС, а также договоров, администрируемых ВОИС. Это связано с тем, что заявившая о себе тенденция к усилению уровня защиты прав ИС, особенно связанная с введением в действие положений ТРИПС-плюс, препятствует масштабному трансферу технологий в развивающиеся страны. Вот почему КРИС и ПКПП большое внимание уделяют гибким возможностям в патентной сфере, предусмотренным в многосторонней нормативной базе, а также широко обсуждают меры по совершенствованию режима ограничений и исключений из патентных прав.

Заключение. По мере развития процессов дальнейшего повышения авторитета стратегии устойчивого развития ВОИС, как и остальные специализированные международные организации системы $\mathrm{OOH}$, разворачивает свою деятельность в направлении создания благоприятных условий для передачи «зеленых» технологий, особенно в наименее развитые страны. Для более детального поворота деятельности организации в этом направлении большую роль сыграла весьма представительная (ученые, представители государственных органов, МПО, НПО, представители бизнес-сообщества, общественности) Конференция по инновациям и изменению климата $(11-12$ июля 2011 года). В рамках конференции проблематика передачи технологии и инно- 
вационного развития была интегрирована в контекст нарастающих глобальных проблем, требующих столь же глобальных решений в области технологической политики.

Как указывает КРИС, задача обеспечения социально-экономического прогресса требует поддержки в получении доступа к существующим низкоуглеродным технологиям и собственных технологических возможностей наименее развитых стран. «Разнообразные технологии также имеют различный потенциал снижения углеродных выбросов и требуют различных политических подходов в разных странах с учетом их международных обязательств» [61]. Продолжением данных инициатив стало создание упомянутой технологической платформы WIPO Green на основе партнерства поставщиков и получателей технологий в сфере охраны окружающей среды. К задачам данной платформы относится повышение скорости адаптации и применения зеленых технологий, в особенности развивающимися странами и странами с растущей экономикой. В рамках данной платформы будут предлагаться технологии, ноу-хау и обслуживание, а пользователи будут размещать в базе данных свои запросы на конкретную технологию. Иначе говоря, платформа позволит не только находить соответствующие «зеленые технологии», но и способствовать их передаче. Предполагается, что условия доступа к технологии в различных целях - для исследовательской работы, производства и/или продажи - будут определяться в индивидуально заключенных договорах.

Все сказанное позволяет сделать вывод о том, что ВОИС со всей ответственностью подходит к вопросу адаптации современной глобальной системы права интеллектуальной, в частности, промышленной собственности к решению задачи содействия передачи технологий в развивающиеся страны. В целом, эффективность проводимой организацией политики в данной тематической сфере будет зависеть от способности развитых и развивающихся стран выработать общие подходы к определению места и значения защиты патентных прав не только для обеспечения государств-реципиентов необходимыми технологиями посредством технологического трансфера, но и для формирования их собственного национального технологического потенциала.

\section{Библиография:}

1. Glass, A.J. and K. Saggi, 1998. International technology transfer and the technology gap. In: Journal of Development Economics, Vol. 55(2): 369-398.

2. Sawada, Y., Matsuda, A. and H. Kimura, 2012. On the role of technical cooperation in international technology transfer. In: Journal of International Development, Vol. 24(3): 316-340.

3. WIPO. Committee on the Law of Patents (SCP) // http://www.wipo.int/policy/en/scp.

4. WIPO. Committee on Development and the Intellectual Property (CDIP) // http://www.wipo.int/policy/en/cdip.

5. Соглашение между ООН и ВОИС. Утверждено резолюцией 3346 (XXIX) Генеральной Ассамблеи ООН от 17 декабря 1974 года // http://www.un.org/ru/documents/decl_conv/conventions/un_wipo_agreement.shtml.

6. WIPO. Colloquia on Selected Patents and Transfer of Technology (November 6, 2007) // http://www.wipo. int/meetings/en/2007/patent_colloquia/11/

7. WIPO Seminar Series on the Economic of IP// http://www.wipo.int/econ_stat/en/economics/seminars.html.

8. The Economics of IP - Patents and Transfer of Technology. WIPO/IP/ECON/GE/6/11 (December 5, 2011, Geneva) // http://www.wipo.int/econ_stat/en/economics/seminars.html.

9. WIPO. The Economics of Intellectual Property // http://www.wipo.int/econ_stat/en/economics.

10. Глобальный обзор ИС «Изменяющееся лицо инноваций» (2011г.) // http://www.wipo.int/econ_stat/en/ economics/wipr/ 
11. Global Innovation Index 2015 // http://www.wipo.int/econ_stat/en/economics/gii.

12. World Intellectual Property Report 2013. Brands: Reputation and Image in the Global Marketplace // http:// www.wipo.int/econ_stat/en/economics/wipr.

13. WIPO. Committee on Development and Intellectual Property (Fourteenth Session, November 10 to 14, 2014). Global knowledge flows. CDIP/14/INF/13 (September 19, 2014) // http://www.wipo.int/edocs/mdocs/mdocs/ en/cdip_14/cdip_14_inf_13.pdf.

14. United Nations, 1964 . The role of patents in the transfer of technology to developing countries. Report of the Secretariat General, UN Publication, New York, 65.II.B.1 // http://www.worldcat.org.

15. General Assembly of United Nations Resolution 1713 (XVI). The role of patents in the transfer of technology to underdeveloped countries. Available at http://daccess-dds-ny.un.org/doc/RESOLUTION/GEN/NR0/167/66/ IMG/NR016766.pdf?OpenElement.

16. General Assembly of United Nations Resolution 2091 (XX). Transfer of technology to developing countries // http://daccess-dds-ny.un.org/doc/RESOLUTION/GEN/NR0/218/54/IMG/NR021854.pdf?OpenElement.

17. Роль патентной системы в передаче технологии развивающимся странам» // TD/B/AC.11/19/Rev.

18. The 45 Adopted Recommendations under the WIPO Development Agenda (2007) // http://www.wipo.int/ ipdevelopment/en/agenda/index.html.

19. WIPO. Development studies// http://www.wipo.int/econ_stat/en/economics/studies.

20. WIPO. Standing Committee on the Law of Patents (Fourteenth Session, Geneva, January 25 to 29, 2010). Transfer of Technology. Document prepared by the Secretariat. SCP/14/4 (December 11, 2009) http://www. wipo.int/edocs/mdocs/scp/en/scp_14/scp_14_4.pdf.

21. WIPO. Standing Committee on the Law of Patents (Fourteenth Session, Geneva, January 25 to 29, 2010). Transfer of Technology. Document prepared by the Secretariat. SCP/14/4.Rev. (April 13, 2011) // http://www. wipo.int/edocs/mdocs/scp/en/scp_16/scp_14_4_rev.pdf.

22. WIPO. Standing Committee on the Law of Patents (Fourteenth Session, Geneva, January 25 to 29, 2010). Transfer of Technology. Document prepared by the Secretariat. SCP/14/4.Rev. 2 (October 26, 2011) // http:// www.wipo.int/edocs/mdocs/scp/en/scp_17/scp_14_4_rev_2.pdf.

23. WIPO. Standing Committee on the Law of Patents (Seventeenth Session, Geneva, December 5 to 9, 2011). Summary by the Chair. SCP/17/12, para 25(e)(ii) (December 9, 2011)// http://www.wipo.int/edocs/mdocs/scp/ en/scp_17/scp_17_12.pdf.

24. WIPO. Standing Committee on the Law of Patents (Eighteenth Session, Geneva, May 21 to 25, 2010). WIPO's activities on transfer of technology. Document prepared by the Secretariat. SCP/18/7. (April 25, 2012) // http:// www.wipo.int/edocs/mdocs/scp/en/scp_18/scp_18_7.pdf.

25. WIPO. Standing Committee on the Law and Patents (Twelfth Session, June $23-27,2008$, Geneva). Report on the International Patent System. SCP/13/3 (April 15, 2008) // http://www.wipo.int/edocs/mdocs/scp/en/ scp_12/scp_12_3.pdf.

26. ВОИС. Договоры по охране интеллектуальной собственности // http://wipo.int/treaties/ru.

27. WIPO Patent Law Treaty, $2000 / /$ http://www.wipo.int/treaties/en/text.jsp?file_id=288996.

28. WIPO Patent Cooperation Treaty, $1970 / /$ http://www.wipo.int/pct/en/texts/articles/atoc.htm.

29. WIPO. The Impacts of TRIPS on Patenting in Latin America: the Different Performance of Residents and Non Residents // WIPO/IP/ECON/GE/5/13 (Octo-ber 22, 2013, Geneva) // http://www.wipo.int/econ_stat/en/ economics/seminars.html.

30. IPRs, Price, and Access to Innovation: Evidence from the TRIPS Agreement // WIPO/IP/ECON/GE/3/13 (June 18, 2013, Geneva) // http://www.wipo.int/econ_stat/en/economics/seminars.html.

31. WIPO. Committee on Development and Intellectual Property (Fourteenth Session, Geneva, November 10 to 14, 2014). Economics of IP and international technology transfer. Ch. 1. Operationalizing Art. 7 of WTO TRIPS: state of art, constraints and prospects. CDIP/14/INF/7 (September 18, 2014) // http://www.wipo.int/ edocs/mdocs/mdocs/en/cdip_14/cdip_14_inf_7.pdf.

32. WIPO. Standing Committee on the Law of Patents (Twentieth Session, Geneva, January 27 to 31, 2014). Patents and transfer of technology: further practical examples and experience. SCP/20/10 (December 4, 2010), para 23 // http://www.wipo.int/edocs/mdocs/scp/en/scp_20/scp_20_10.pdf. 
33. WIPO. Projects for Implementation of Development Agenda recommendations (Projects for Recommendations 2, 5, 8, 9 and 10). Thematic Projects // http://www.wipo.int/ip-development/en/agenda/projects.html.

34. WIPO. Committee on Development and Intellectual Property (Third Session, Geneva, April 27 to May 1, 2009). Project documents for implementation of Recommendations 2, 5, 8, 9 and $10 / / \mathrm{CDIP} / 3 / \mathrm{INF} / 2$ Annex VII (March 30, 2009) // http://www.wipo.int/edocs/mdocs/mdocs/en/cdip_3/cdip_3_inf_2.pdf.

35. Project Documents for implementation of Recommendations 2, 5, 8, 9 and 10. CPIP. Third Session, Geneva, April 27 to May 1, 2009). CDIP/3/INF/2. Annex III // http://www.wipo.int/edocs/mdocs/mdocs/en/cdip_3/ cdip_3_inf_2.pdf.

36. WIPO. ARDI - Research for Innovation // http://www.wipo.int/ardi/en/

37. WIPO. ASPI - Specialized Patent Information // http://www.wipo.int/aspi.

38. WIPO Technology and Innovation Support Center (TISC) Program // http://www.wipo.int/tisc.

39. WIPO. Project on Developing Tools for Access to Patent Information (Recommendations 19, 30 and 31). CDIP/4/6 (September 25, 2009) // http://www.wipo.int/meetings/en/details.jsp?meeting_id=17460.

40. WIPO. Conference on IP and Public Policy Issues (July 13 and 14, 2009) // http://www.wipo.int/meetings/ en/2009/ip_gc_ge/index.html.

41. WIPO Technology and Innovation Support Center (TISC) Program // http://www.wipo.int/tisc.

42. Committee on Development and Intellectual property. (Fourth Session, Geneva, November 16 to 20, 2009). Project on Intellectual Property and Technology Transfer: Common Challenges: Building Solutions (Recommendations 19, 25, 26 and 28). CDIP/4/7 // http://www.wipo.int/edocs/mdocs/mdocs/en/cdip_4/cdip_4_7.pdf.

43. Project on IP and Technology Transfer: Common Challenges - Building Solutions (Recommendations 19, 25, 26, 28). CDIP/6/4 Rev. (November 26, 2010)//http://www.wipo.int/meetings/en/doc_details.jsp?doc_id=156582.

44. Project Paper for IP and Technology Transfer: Common Challenges - Building Solutions (Recommendations 19, 25, 26, 28). CDIP/8/7. (October 26, 2011) http://www.wipo.int/edocs/mdocs/mdocs/en/cdip_8/cdip_8_7.pdf.

45. WIPO. Committee on Development and Intellectual Property. (Ninth Session, Geneva, May 7 to 11, 2012). Revised Project Paper for the Project on Intellectual Property and Technology transfer Common ChallengesBuilding Solutions (Recommendations 19, 25, 26 and 28), para 22 CDIP/9/INF/4 (March 13, 2012) // http:// www.wipo.int/edocs/mdocs/mdocs/en/cdip_9/cdip_9_inf_4.pdf.

46. Discussions on Implementation of Recommendations on Technology Transfer at the Fourth Session of the CDIP Held From November 16 to 20, 2009 (Extracted From CDIP/4/14 Prov.) // http://www.wipo.int/edocs/ $\mathrm{mdocs} / \mathrm{mdocs} / \mathrm{en} / \mathrm{cdip} 5 / \mathrm{cdip} 5$ _ref_cdip_4_14.pdf.

47. WIPO. Committee on Development and Intellectual Property. (Sixteenth Session, November 9 to 13, 2015). Evaluation Report of the Project on IP and Technology Transfer Common Challenges - Building Solutions (August 10, 2015). CDIP 16/3// http://www.wipo.int/edocs/mdocs/mdocs/en/cdip_16/cdip_16_3.pdf.

48. WIPO. Committee on Development and Intellectual Property. (Fourteenth Session, November 10 to 14, 2014). Concept paper for the Project on IP and Technology Transfer: Common Challenges - Building Solutions (Recommendations 19, 25, 26 and 28). CDIP/14/8 Rev. 2 (November 14, 2014) // http://www.wipo.int/edocs/ $\mathrm{mdocs} / \mathrm{mdocs} / \mathrm{en} / \mathrm{cdip}$ 14/cdip_14_8_rev_2.pdf.

49. WIPO. Committee on Development and Intellectual Property. (Fifteenth Session, April 20 to 24, 2015). Report on the WIPO Expert Forum on international technology transfer (March 2, 2015). CDIP/15/5 // http://www. wipo.int/edocs/mdocs/mdocs/en/cdip_15/cdip_15_5.pdf.

50. WIPO. Committee on Development and Intellectual Property (CDIP). (Fourteenth Session, November 10 to 14, 2014). Concept paper for the Project on IP and Technology Transfer: Common Challenges - Building Solutions (Recommendations 19, 25, 26 and 28). CDIP/14/8 Rev. 2 (November 14, 2014) // http://www.wipo. int/edocs/mdocs/mdocs/en/cdip_14/cdip_14_8_rev_2.pdf.

51. WIPO Expert Forum on international technology transfer (February 16 to 18, 2015, Geneva). WIPO/INN/ GE/15 // http://www.wipo.int/meetings/en/details.jsp?meeting_id=35562.

52. WIPO. Committee on Development and Intellectual Property (CDIP). (Fourteenth Session, November 10 to 14, 2014). Policies fostering the participation of business in technology transfer. CDIP/14/INF/10 (September 18, 2014) // http://www.wipo.int/edocs/mdocs/mdocs/en/cdip_14/cdip_14_inf_10.pdf.

53. A/RES/35/63 "Restrictive business practices" (5 December 1980) // http://www.un.org/documents/ga/res/35/ a35r63e.pdf. 
54. WIPO Survey on Technology Transfer Agreements and Antitrust. Prepared by the Secretariat (December 2013) // http://www.wipo.int/export/sites/www/ip-competition/en/studies/tta_survey.pdf.

55. Nguyãĕn, T., 2010. Competition law, technology transfer and the TRIPS Agreement: implications for developing countries. Edward Elgar Publishing, Cheltenham.

56. WIPO Survey on the Antitrust Dimension on Intellectual property Licensing Agreements in Support of technology Transfer. Prepared by the Secretariat (May 2015) // http://www.wipo.int/export/sites/www/ip-competition/en/studies/technology_transfer_survey.pdf.

57. WIPO. CDIP. Неофициальный документ по ИС и передаче технологий «Общие проблемы-построение решений». Неофициальный документ № 1. CDIP/5(R) (12/03/2010). Приложение II // http://www.wipo. int/edocs/mdocs/mdocs/en/cdip_5/cdip_5_ref_non_paper.pdf.

58. WIPO. Committee on Development and Intellectual property. (Fourth Ses-sion, Geneva, November 16 to 20, 2009). Comments received by WIPO on the Comments of a Group Like-Minded Countries on the Project on Intellectual Property and Technology Transfer: Common Challenges: Building Solutions (CDIP/4/7). Annex // http://www.wipo.int/meeting/en/details.jsp?meeting_id=17460.

59. WIPO. Committee on Development and Intellectual Property (Fourteenth Session, Geneva, November 10 to 14, 2014). IP-related policies and initiatives in developed countries to promote technology transfer. Committee on Development and Intellectual Property (CDIP). (Fourteenth Session, November 10 to 14, 2014). CDIP/14/ INF/8 (September 23, 2014) // http://www.wipo.int/edocs/mdocs/mdocs/en/cdip_14/cdip_14_inf_8.pdf.

60. WIPO. Committee on Development and Intellectual Property. International technology transfer an analysis from the perspective of developing countries. (Fourteenth Session, November 10 to 14, 2014, Geneva). CDIP/14/ INF/11 (Sep-tember 19, 2014) // http://www.wipo.int/edocs/mdocs/mdocs/en/cdip_14/cdip_14_inf_11.pdf.

61. WIPO. Committee on Development and Intellectual Property. (Ninth Session, Geneva, May 7 to 11,2012 ). Revised Project Paper for the Project on Intellectual Property and Technology Transfer: Common Challenges - Building Solutions (Recommendations 19, 25, 26 and 28), para 22 of CDIP/9/INF/4 (March 13, 2012) // http://www.wipo.int/edocs/mdocs/mdocs/en/cdip_9/cdip_9_inf_4.pdf.

62. Шугуров М.В. Международно-правовое регулирование передачи технологий в целях развития // Право и политика. - 2013. - 8. - C. 1032 - 1046. DOI: 10.7256/1811-9018.2013.8.9066.

\section{References (transliterated):}

1. Glass, A.J. and K. Saggi, 1998. International technology transfer and the technology gap. In: Journal of Development Economics, Vol. 55(2): 369-398.

2. Sawada, Y., Matsuda, A. and H. Kimura, 2012. On the role of technical cooperation in international technology transfer. In: Journal of International Development, Vol. 24(3): 316-340.

3. Nguyãẽn, T., 2010. Competition law, technology transfer and the TRIPS Agreement: implications for developing countries. Edward Elgar Publishing, Cheltenham.

4. Shugurov M.V. Mezhdunarodno-pravovoe regulirovanie peredachi tekhnologii v tselyakh razvitiya // Pravo i politika. - 2013. - 8. - C. 1032 - 1046. DOI: 10.7256/1811-9018.2013.8.9066. 